Article

\title{
Hot Deformation Behaviors of the Mg-3Sn-2Al-1Zn Alloy: Investigation on its Constitutive Equation, Processing Map, and Microstructure
}

\author{
Yuhang Guo ${ }^{1,2, * \mathbb{C}}$, Yaodong Xuanyuan ${ }^{1}$, Xuannam Ly $^{1}$ and Sen Yang ${ }^{1, *}$ \\ 1 School of Materials Science and Engineering, Nanjing University of Science and Technology, Nanjing 210094, \\ China; xuanyuanyaodong@outlook.com (Y.X.); lyxuannam@yahoo.com (X.L.) \\ 2 School of Material Science and Engineering, Jiangsu University of Science and Technology, \\ Zhenjiang 212003, China \\ * Correspondence: guoyuhang@just.edu.cn or guoyuhang@126.com (Y.G.); yangsen@njust.edu.cn (S.Y.); \\ Tel.: +86-511-84401188 (Y.G.)
}

Received: 27 November 2019; Accepted: 6 January 2020; Published: 9 January 2020

\begin{abstract}
In this work, the Mg-3Sn-2Al-1Zn (TAZ321, wt. \%) alloy with excellent high temperature resistance was compressed using a Gleeble-3500 thermo-mechanical simulator at a wide temperature and the strain rate range. The kinetics analyses showed that the dominant deformation mechanism was likely caused by the cross slipping of dislocations. A constitutive equation which expressed the relationship between the flow stress, deformation temperature, and strain rate was established, and the average activation energy $Q$ was calculated to be $172.1 \mathrm{~kJ} / \mathrm{mol}$. In order to delineate the stability and instability working domains, as well as obtain the optimum hot working parameters of the alloy, the hot processing maps in accordance with Prassad's criterion are constructed at the true strain of $0.2,0.4,0.6$, and 0.8 , respectively. Based on the hot processing map and microstructure observation, the optimum hot working parameter was determined to be $350^{\circ} \mathrm{C} / 1 \mathrm{~s}^{-1}$. The continuous fine dynamic recrystallization $(C D R X)$ grains occurred in the optimum deformation zone. The predicted instability domains was identified as $\mathrm{T}=200-300^{\circ} \mathrm{C}, \dot{\varepsilon}=10^{-2}-1 \mathrm{~s}^{-1}$, which corresponded to the microstructure of deformation twinning and micro cracks at the intersection of grain boundaries.
\end{abstract}

Keywords: Mg-Sn alloy; hot deformation; constitutive equation; processing maps

\section{Introduction}

Recently, the Mg-Sn alloy has been considered as a typical heat-resistance magnesium alloy owing to the existence of high melting $\mathrm{Mg}_{2} \mathrm{Sn}$ phases $\left(\mathrm{T}_{\mathrm{m}}-770{ }^{\circ} \mathrm{C}\right)[1,2]$, which have a strong potential for high temperature structural applications. Therefore, it is essential to investigate the hot deformation behaviors in order to design of superior performance $\mathrm{Mg}$-Sn alloys.

To our knowledge, several works have been done on the hot deformation behaviors of $\mathrm{Mg}-\mathrm{Sn}$ alloys [3-6]. An example of this is the hot deformation behaviors and optimum processing parameters of homogenized TAZ811 alloy and fine-grained TZA822 alloy investigated by using a processing map and microstructural evolution. The practical processing window of homogenized TAZ811 alloy was determined as $\mathrm{T}=350-400{ }^{\circ} \mathrm{C}$ and $\dot{\varepsilon}=0.33-3.3 \mathrm{~s}^{-1}$, while the dominant high temperature deformation mechanisms were controlled by a climbing of dislocation [6]. In addition, the optimum hot working parameters for the fine-grained TZA822 alloy were determined to be $350{ }^{\circ} \mathrm{C} / 0.01 \mathrm{~s}^{-1}$ and $350{ }^{\circ} \mathrm{C} / 10 \mathrm{~s}^{-1}$, at which point continuous DRX (CDRX) and discontinuous DRX (DDRX) were the main softening mechanisms [5]. In contrast to the Mg-8Sn based alloys with high Sn content, Mg-3Sn based alloys with a lower amount of Sn did not only decrease the density and solid solution temperature of alloy [7], but also exhibited higher tensile strength and elongation [8]. However, the knowledge on the 
hot deformation behaviors of the Mg-3Sn alloy in the literature mainly focuses on the $\mathrm{Mg}-3 \mathrm{Sn}-1 \mathrm{Ca}$ alloy [3,4]. Rao, K.P. et al. reported that there are two stable domains for the as-cast and homogenized $\mathrm{Mg}-3 \mathrm{Sn}-1 \mathrm{Ca}$ alloy, both of which are in the temperature range $350-550{ }^{\circ} \mathrm{C}$ : one is in the lower strain rate range $\left(0.0003-0.01 \mathrm{~s}^{-1}\right)$ and the other is found at higher strain rates $\left(1-10 \mathrm{~s}^{-1}\right)$ [4].

Compared with the $\mathrm{Mg}-3 \mathrm{Sn}-1 \mathrm{Ca}$ alloy adopting $\mathrm{Ca}$, the minor addition of $\mathrm{Al}$ or $\mathrm{Zn}$ as the solid solution strengthening element could enhance the strength [9], age hardening response [10], and strain hardening ability [11] of Mg-Sn based alloys. However, limited research was conducted on the hot deformation behaviors of Mg-3Sn-Al-Zn system alloys. Based on the above consideration, we designed the alloy with nominal composition of Mg-3Sn-2Al-1Zn (wt. \%) and investigate the hot deformation behaviors of the alloys in terms of a kinetic analysis, hot processing map, and microstructure evolution. Additionally, hot deformation mechanisms and dynamic recrystallization (DRX) behaviors during the hot deformation process were also analyzed and discussed.

\section{Experimental Procedure}

The alloy ingots with the nominal composition of Mg-3Sn-2Al-1Zn (wt. \%) were prepared using an electric furnace with a covering flux under a protective atmosphere $\left(0.5\right.$ vol. $\% \mathrm{SF}_{6}+99.5$ vol. $\left.\% \mathrm{CO}_{2}\right)$. The melt was held at $720^{\circ} \mathrm{C}$ for $20 \mathrm{~min}$ and mechanically stirred for $2 \mathrm{~min}$ to ensure a homogeneous composition, then the pouring was accomplished into a steel die preheated up to $150{ }^{\circ} \mathrm{C}$. After casting, the cast billets were homogenized at $400{ }^{\circ} \mathrm{C}$ for $24 \mathrm{~h}$. The actual composition of as-cast and as-homogenized TAZ321 alloy measured using energy dispersive X-ray spectroscopy (EDS, Oxford Instruments Inc, Abingdon, UK) is listed in Table 1. Then the cylindrical samples with a diameter of $10 \mathrm{~mm}$ and a height of $15 \mathrm{~mm}$ were machined using an electro discharge-cutting machine. Compression tests were conducted on a Gleeble-3500 thermo-mechanical simulator (Dynamic Systems Inc., New York, NY, USA) at the temperature range of $200-350{ }^{\circ} \mathrm{C}$ and a strain rate of $10^{-3}-1 \mathrm{~s}^{-1}$. Mo plates covered with boron nitride powder were used as lubrication for minimizing the effect of friction. Before deformed, the samples were heated at a heating rate of $5 \mathrm{~K} / \mathrm{s}$, and followed by a holding time of $10 \mathrm{~min}$ for ensuring there were uniform temperature throughout the samples. In order to freeze the microstructure, all post-deformation samples were cooled by water-quench up to a true strain of 0.8 . The microstructural examinations specimens were sliced in the center parallel to the compression axis.

The phase structure of as-homogenized TAZ321 alloy was identified by Parnike X' Pert PRO MPD (Holland Panalytical, Almelo, The Netherlands) X-ray diffraction (XRD) diffractometer with $\mathrm{Cu}$ radiation. The microstructure of the as-homogenized and post-deformation samples were examined using an AxioImager A2m (ZEISS Inc., Oberkochen, Germany) optical microscope (OM), a MALA3 Triglay (TESCAN Inc., Brno, Czech) scanning electron microscope (SEM) equipped with EDS, and a 2100 F (JEOL Inc., Tokyo, Japan) transmission electron microscope (TEM). Additionally, the electron backscatter diffraction (EBSD) micro orientation analysis of the as-homogenized and post-deformation samples was conducted using an Oxford Instruments-NordlysNano EBSD detector (Oxford Instruments Inc., Abingdon, UK) equipped on the SEM operating at $20 \mathrm{kV}$. The samples prepared for EBSD analysis were additionally developed by ion etching in a Leica RES101 ion etching apparatus (Bal-Tec, Inc., Wetzlar, Germany) after mechanical polishing. The orientation imaging microscopy software used for post-EBSD data analysis was provided by HKL Channel 5.11.20405.0, Oxford Instruments NanoAnalysis, Abingdon, UK.

Table 1. Actual composition (wt. \%) of the as-cast and as-homogenized TAZ321 alloy.

\begin{tabular}{ccccc}
\hline Alloy & Mg & Sn & Al & Zn \\
\hline As-cast & $93.87 \pm 0.46$ & $3.45 \pm 0.21$ & $1.64 \pm 0.18$ & $1.05 \pm 0.07$ \\
As-homogenized & $93.50 \pm 0.26$ & $3.47 \pm 0.3$ & $1.8 \pm 0.23$ & $1.23 \pm 0.32$ \\
\hline
\end{tabular}




\section{Results and Discussion}

\subsection{Microstructural Characterization and Analyze of the as-Homogenized TAZ321 Alloy}

Figure 1 shows the initial microstructure of the as-homogenized TAZ321 alloy. XRD results (Figure 1a) exhibit that the alloy is mainly composed of $\alpha$-Mg phases, and some weak peaks representing $\mathrm{Mg}_{2} \mathrm{Sn}$ phases can also be observed. Based on the SEM and EDS results (Figure 1b), the undissolved spherical and/or cubic $\mathrm{Mg}_{2} \mathrm{Sn}$ phases distribute homogeneously into the $\alpha-\mathrm{Mg}$ matrix. An EBSD inverse pole map (IPF) (Figure 1c) and grain distribution statistic (Figure 1d) show that the grain size ranged from 40 to $200 \mu \mathrm{m}$ with random grain orientations, and the average grain size was determined to be $104.47 \mu \mathrm{m}$.

(a)

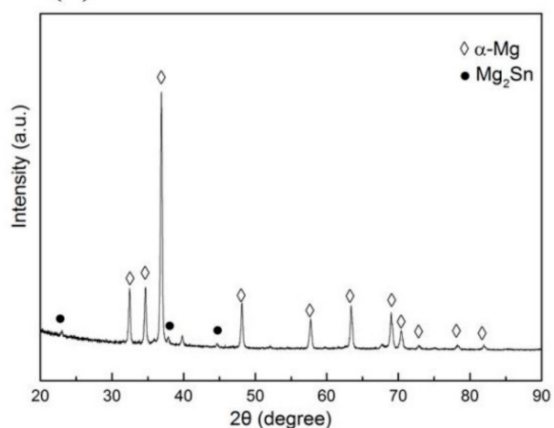

(c)

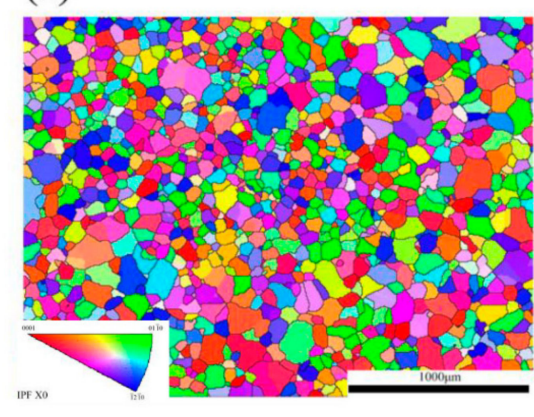

(b)

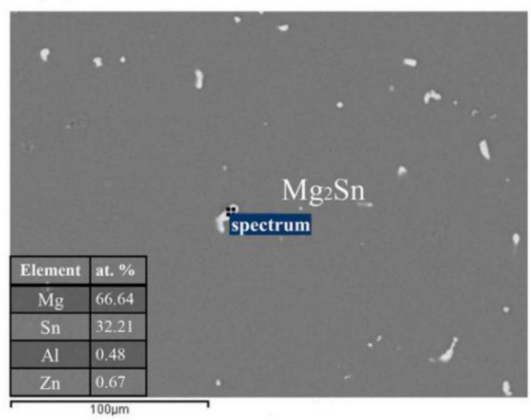

(d)

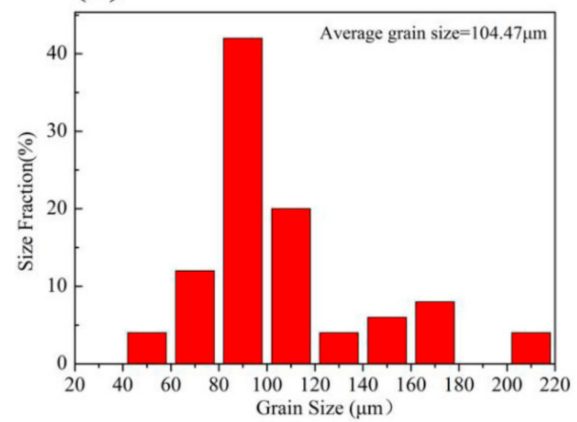

Figure 1. The microstructure of the as-homogenized TAZ321 alloy: (a) XRD; (b) SEM and EDS; (c) Inverse pole map; (d) Grain distribution statistic.

\subsection{Flow Stress Curves Analysis}

The true stress-strain curves of the homogenized TAZ321 alloy under different temperature and strain rates at a true strain of 0.8 are indicated in Figure 2. The flow curves initially increase to a peak value and then decrease and finally reach a steady state. Such flow behavior is a typical characteristic for hot working accompanied by work hardening and dynamic softening. The work hardening was induced generally by the generation and multiplication of dislocation, while the dynamic softening was related to the DRX and/or DRV [12]. In addition, the flow stress decreased with the decreasing of the strain rate, which was attributed to a more adequate time for the mobility of grain boundaries and dislocation at a lower strain rate.

Furthermore, it was interestingly found that obvious serration behaviors can be observed in the true stress-strain curves. The type of serrations was associated with the deformation temperature and strain rate, as well as the extent of deformation, which can be attributed to the interaction effect between the dislocation and precipitation and/or solute atoms, i.e., the dynamic strain aging (DSA) effect $[13,14]$. It is thought to be when a dislocation movement is hindered by obstacles, solute atoms will segregate preferentially by means of pipe diffusion in the vicinity of the obstacle, resulting in the formation of solute cluster, which can strongly pin the dislocation, leading to the stress increase. 
Meanwhile, the pinning dislocation will be released due to thermal activation and then cause a stress decrease. Thus, serrated behaviors during deformation can be understood as the circulation of pinning and releasing of mobile dislocations. Based on the serration morphologies, the serration type can be categorized. Type A is manifested by the stress sudden rise and then by dropping to a general level at a random frequency. Type B is also called the "hopping band", and is characterized by the appearance of oscillation above and below the average value of stress in quick succession, and type $C$ is defined as stress fluctuation with a higher amplitude and frequency in comparison with type B [14]. It should be noted that the serrations morphology is indicative for type B for the TAZ321 alloy, which was attributed to the interaction of the dislocation and the dynamic precipitation of $\mathrm{Mg}_{2} \mathrm{Sn}$ particles, as illustrated in Figure 3.

(a)

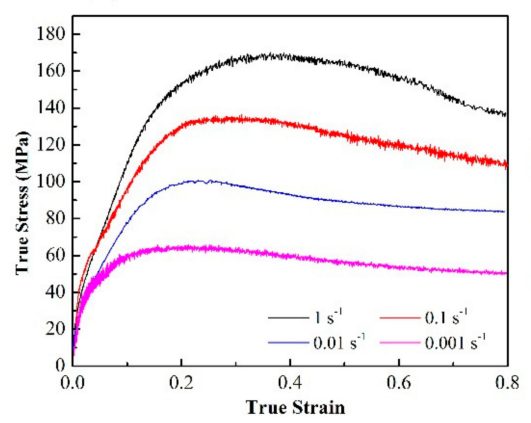

(c)

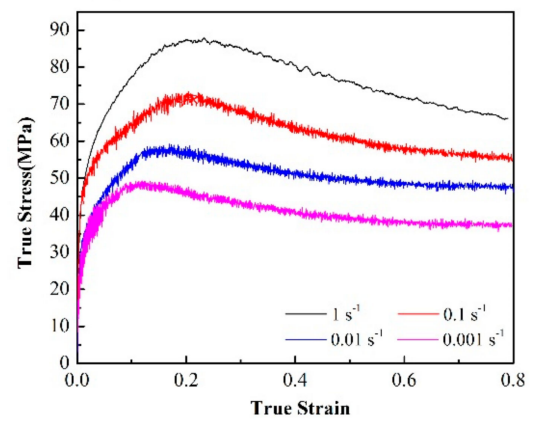

(b)

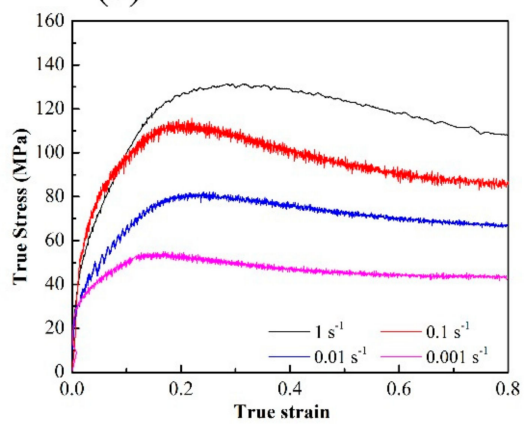

(d)

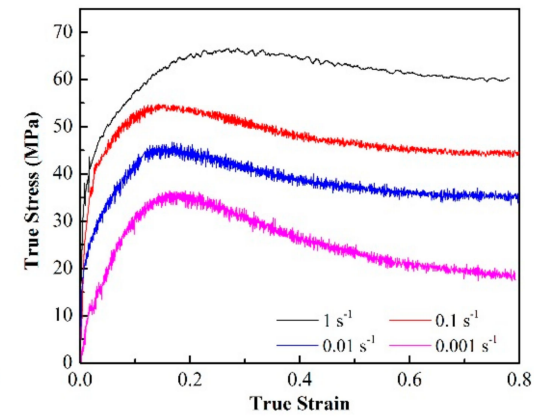

Figure 2. True stress-true strain curves of as-homogenized TAZ321 alloy at different strain rates with temperature: (a) $200{ }^{\circ} \mathrm{C}$; (b) $250{ }^{\circ} \mathrm{C}$; (c) $300{ }^{\circ} \mathrm{C}$; (d) $350{ }^{\circ} \mathrm{C}$.

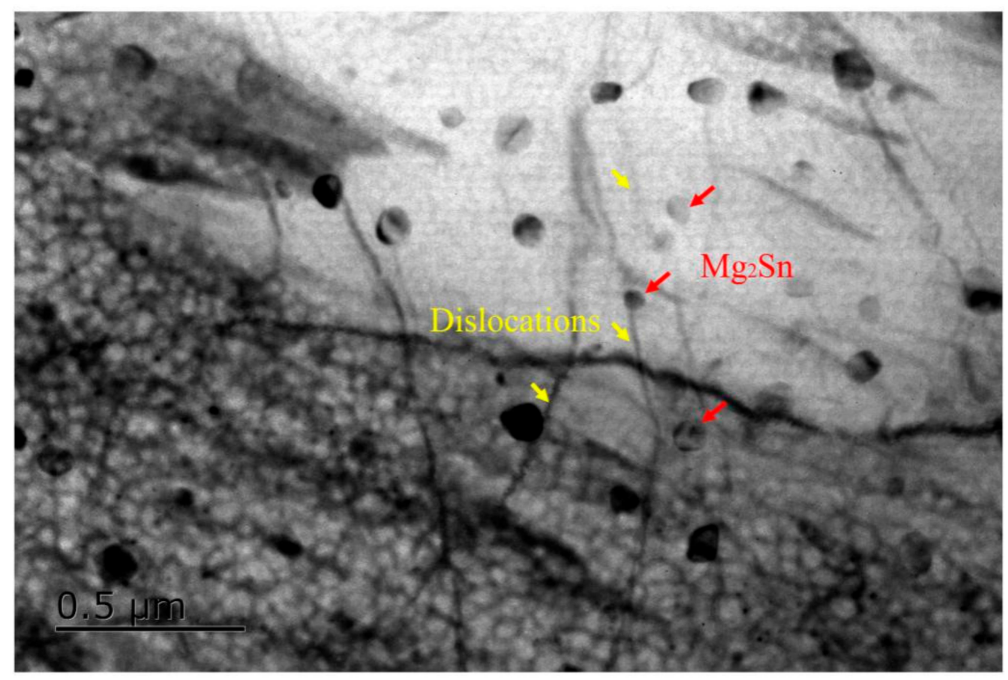

Figure 3. The interaction effect between dislocations and $\mathrm{Mg}_{2} \mathrm{Sn}$ particles of the homogenized TAZ321 alloy deformed at $200{ }^{\circ} \mathrm{C} / 10^{-3} \mathrm{~s}^{-1}$. 


\subsection{Constitutive Analysis}

For the metal materials, there are three different constitutive models (power, exponential, or hyperbolic sine law) can be used to express the relationship among the strain rate $(\dot{\varepsilon})$, deformation temperature $(\mathrm{T})$, and flow stress $(\sigma)$ for different deformation conditions. The power, exponential or hyperbolic sine law can be described by Equations (1)-(3), respectively [15]:

$$
\begin{gathered}
\dot{\varepsilon}=\mathrm{A}_{1} \sigma^{\mathrm{n}_{1}} \quad(\alpha \sigma<0.8) \\
\dot{\varepsilon}=\mathrm{A}_{2} \exp (\beta \sigma) \quad(\alpha \sigma>1.2) \\
\mathrm{Z}=\dot{\varepsilon} \exp \left(\frac{\mathrm{Q}}{\mathrm{RT}}\right)=\mathrm{A}[\sinh (\alpha \sigma)]^{\mathrm{n}} \quad \text { (universal) }
\end{gathered}
$$

where $\mathrm{Z}$ is the Zener-Hollomon parameter, $\mathrm{A}, \mathrm{A}_{1}, \mathrm{~A}_{2}, \mathrm{n}_{1}$, and $\beta$ are the material constants. $\alpha$ is the stress multiplier, $\mathrm{n}$ is the stress exponent, $\mathrm{Q}$ is the activation energy of hot deformation $\left(\mathrm{kJ} \mathrm{mol}^{-1}\right)$, and $\mathrm{R}$ is the gas constant $\left(8.314 \mathrm{~J} \mathrm{~mol}^{-1} \mathrm{~K}^{-1}\right)$. Taking natural logarithm simultaneously on both sides of Equations (1)-(3), the following equations were obtained, namely:

$$
\begin{gathered}
\ln \dot{\varepsilon}=\ln \mathrm{A}_{2}+\beta \sigma-\frac{\mathrm{Q}}{\mathrm{RT}} \\
\ln \dot{\varepsilon}=\ln \mathrm{A}_{1}+\mathrm{n}_{1} \ln \sigma-\frac{\mathrm{Q}}{\mathrm{RT}} \\
\ln \mathrm{Z}=\ln \dot{\varepsilon}+\frac{\mathrm{Q}}{\mathrm{RT}}=\ln \mathrm{A}+\mathrm{n} \ln [\sinh (\alpha \sigma)] .
\end{gathered}
$$

In general, the power law was adopted for the low stress level $(\alpha \sigma<0.8)$, the exponential law was suitable at a high stress level $(\alpha \sigma>1.2)$, while the sine hyperbolic law combined the power law and the exponential law to break the stress limits and can be considered as a suitable candidate for wide deformation conditions. Therefore, the sine hyperbolic law model was employed for the homogenized TAZ321 alloy.

By linear fitting the relationship of $\ln \dot{\varepsilon}-\sigma$ and $\ln \dot{\varepsilon}-\ln \sigma$ in Figure $4 \mathrm{a}, \mathrm{b}$, the average values of $\mathrm{n}_{1}$ and $\beta$, i.e., the linear slope of the plots, can be obtained as 9.1859 and 0.01064 . Thus, the value of $\alpha$ can be calculated as 0.001158. After submitting the value of $\alpha$ into Equation (6), the linear relationship can be determined (Figure 4c). The average value of stress exponent was equal to the slope of $\ln \dot{\varepsilon}-\ln \sinh \sigma_{\mathrm{P}}$ and was obtained as 6.22. For the $\mathrm{Mg}$ alloy, the value of stress exponent $\mathrm{n}$ represents the hot deformation mechanisms during the process of hot deformation. The range of this exponent was $n=4-6$ during the dislocation climb, and while the value of $n$ ranged from 6 to 7 , the cross-slip of screw dislocations were the main deformation mechanisms $[5,16]$. For the present as-homogenized TAZ321 alloy, the average value of $n$ was close to that of fine-grained TZA822 alloy $(n=6.45)$, indicating that the dominant deformation mechanism was likely controlled by dislocation cross-slip.

In addition, by taking partial differential on both sides of Equation (4), the activation energy $Q$ associated with diffusion and the precipitation of particles could be conveyed as:

$$
\mathrm{Q}_{\text {eff }}=\mathrm{R} \cdot \mathrm{S} \cdot \mathrm{N}=\mathrm{R} \cdot\left\{\frac{\partial(\ln \dot{\varepsilon})}{\partial \ln \left[\sinh \left(\alpha\left(\sigma_{\mathrm{p}}-\sigma_{0}\right)\right)\right]}\right\}_{\mathrm{T}} \cdot\left\{\frac{\partial \ln \left[\sinh \left(\alpha\left(\sigma_{\mathrm{p}}-\sigma_{0}\right)\right)\right]}{\partial\left(\frac{1000}{\mathrm{~T}}\right)}\right\}_{\dot{\varepsilon}} .
$$

The value of $S$ was equal to the slope of the plots of $\ln \sinh \left(\sigma_{p}\right)-\frac{1000}{T}$, as shown in Figure $4 \mathrm{~d}$. The average value of $Q$ of the alloy was calculated as $172.1 \mathrm{~kJ} / \mathrm{mol}$, which was slightly lower than the activation energy of homogenized TAZ811 alloy $(-187.2 \mathrm{~kJ} / \mathrm{mol})$ [6] and fine-grained TZA822 alloy $(-189.5 \mathrm{~kJ} / \mathrm{mol})$ [5], and was higher than that of AZ61 alloy (-140 kJ/mol) [17] and Mg-3Zn-0.8Zr alloy $(-124.6 \mathrm{~kJ} / \mathrm{mol})$ [18]. The higher $\mathrm{Q}$ value indicated the existence of desperate $\mathrm{Mg}_{2} \mathrm{Sn}$ particles, which can provide back stress to hinder the movement of dislocation, resulting in higher $Q$ values. 


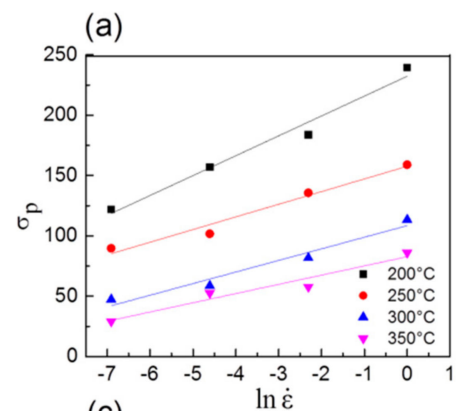

(b)
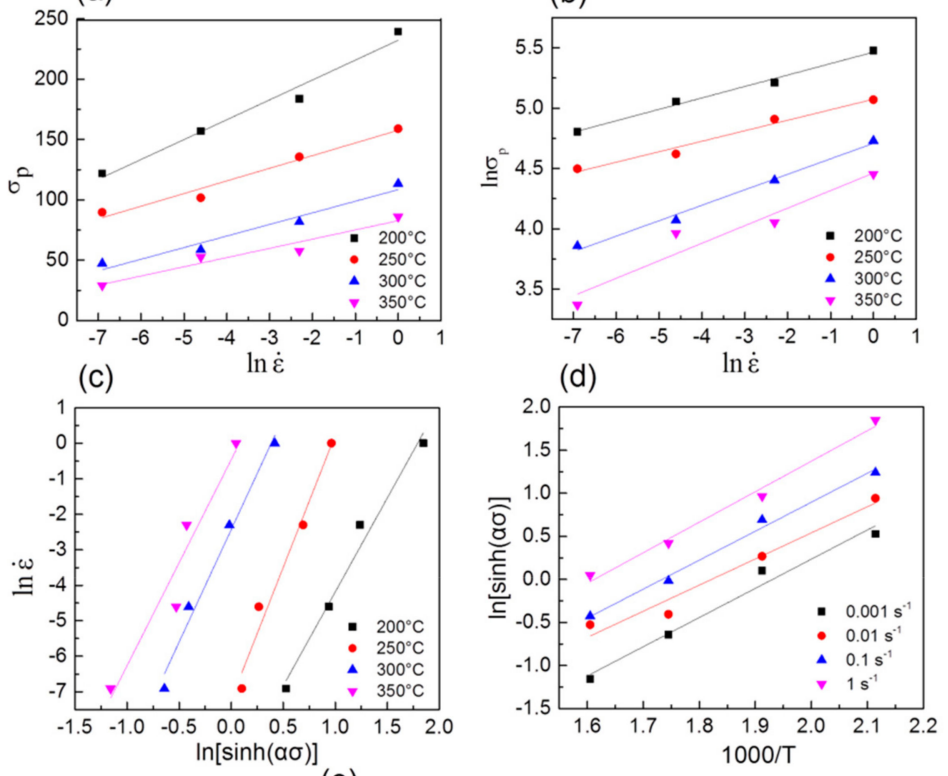

(e)

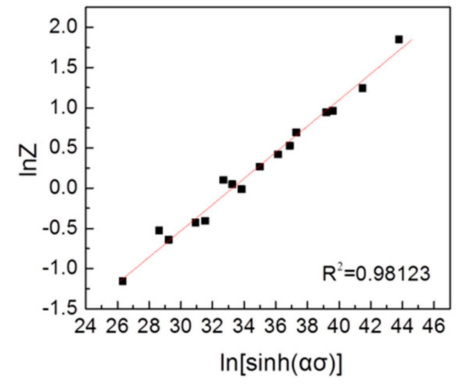

Figure 4. Relationship between (a) $\ln \dot{\varepsilon}-\sigma_{\mathrm{p}},(\mathbf{b}) \ln \dot{\varepsilon}-\ln \sigma_{\mathrm{p}},(\mathbf{c}) \ln \dot{\varepsilon}-\ln \sinh \left(\sigma_{\mathrm{p}}\right),(\mathbf{d}) \ln \sinh \left(\sigma_{\mathrm{p}}\right)-\frac{1000}{\mathrm{~T}}$, and $(\mathbf{e}) \ln Z-\ln [\sinh (\alpha \sigma)]$, respectively.

Moreover, the corresponding value of $\mathrm{A}$ and $\mathrm{n}$ could be determined as $2.78 \times 10^{14}$ and 6.14 by the regression analysis of the intercept of plots of $\ln Z-\ln [\sinh (\alpha \sigma)]$ based on Equation (6), as indicated in Figure 4e. The correlation coefficient $\left(R^{2}=0.9892\right)$ was almost 1 , validating that the hyperbolic sine model matched well with the experiment data. Finally, substituting the corresponding parameters into the Equation (1), the constitutive equation of the homogenized TAZ321 alloy was obtained as follows:

$$
\dot{\varepsilon}=2.78 \times 10^{14} \cdot[\sinh (0.0012 \sigma)]^{6.14} \cdot \exp \left(-\frac{172110}{8.314 \mathrm{~T}}\right) .
$$

\subsection{Processing Maps}

Materials engineers usually get the optimum working parameters of the alloys by utilizing the hot processing map on the basis of the dynamic materials model (DMM), i.e., Prassad's criterion [19]. It was proven to be an effective tool for understanding the hot deformation behaviors of metallic alloys, such as titanium alloys [20,21], twinning induced plasticity (TWIP) steels [22] and super-alloys [23].

The hot processing maps were overlapped by the power dissipation map and instability map based on the DMM model, and the overall total power P was considered as the sum of G and J. G is the power dissipation value caused by plastic deformation, and $\mathrm{J}$ is power dissipation related to the microstructural evolution, such as during phase transformation, DRV, and DRX. The allocation of $\mathrm{P}$ for the $\mathrm{G}$ and $\mathrm{J}$ was determined by a strain rate sensitivity parameter $\mathrm{m}$, which can be expressed by the formula as [24]:

$$
\mathrm{m}=\frac{\partial \mathrm{J}}{\partial \mathrm{G}}=\frac{\partial(\ln \sigma)}{\partial(\ln \dot{\varepsilon})}
$$


In addition, for a non-linear power dissipater, the capacity of power dissipation was expressed by means of a power dissipation $(\eta)$ equation given by [24]:

$$
\eta=\frac{2 m}{2 m+1}
$$

where $\mathrm{m}$ is the strain rate sensitivity. The flow instability region can be predicted by the instability parameter $\xi(\dot{\varepsilon})$, which is given by Equation (11) [24]:

$$
\xi(\dot{\varepsilon})=\frac{\partial \lg \left(\frac{\mathrm{m}}{\mathrm{m}+1}\right)}{\partial \lg \dot{\varepsilon}}+\mathrm{m} \leq 0 .
$$

When the value of $\xi(\dot{\varepsilon})$ is negative, flow instability regions occur in the deformed samples, which are characterized by the presence of cracks, local flow, and adiabatic shear band in the microstructure [25].

Figure 5 shows the hot processing maps of the as-homogenized TAZ321 alloy at different true strain, in which the contour represents the power dissipation efficiency as a percentage and the gray shadow regions denote the regimes of flow instability. There are two common stability domains (domain A and domain B) with the relatively higher power efficiency at different true strain levels. Domain $\mathrm{A}$ is located at $\mathrm{T}=310-350{ }^{\circ} \mathrm{C}$ and $\dot{\varepsilon}=10^{-1}-1 \mathrm{~s}^{-1}$, corresponding to the value of activation range from $160.5 \mathrm{~kJ} / \mathrm{mol}$ to $176.7 \mathrm{~kJ} / \mathrm{mol}$. Domain $\mathrm{B}$ is observed at $\mathrm{T}=310-350{ }^{\circ} \mathrm{C}, \dot{\varepsilon}=10^{-3}-10^{-2} \mathrm{~s}^{-1}$, corresponding to a value of activation which ranged from $146.2 \mathrm{~kJ} / \mathrm{mol}$ to $178.1 \mathrm{~kJ} / \mathrm{mol}$. In addition, the area fraction of instability domains decreased with the increasing true strain. Commonly, domains with the high $\eta$ value in stability regions are treated as the ideal processing windows, which also need to further confirmed by the microstructures of deformed samples [6,12].

(a)

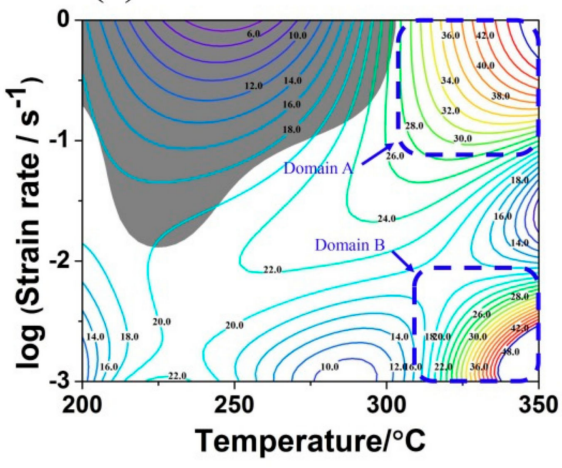

(c)

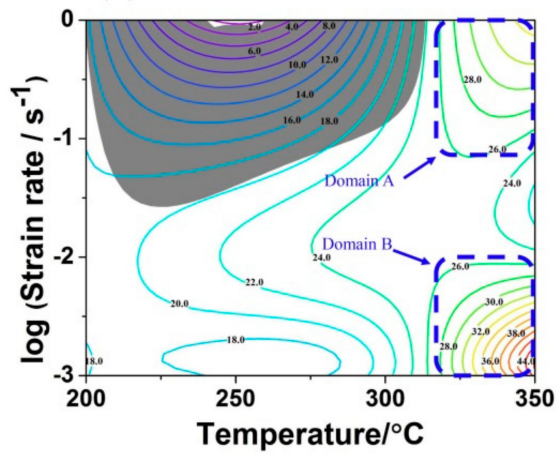

(b)

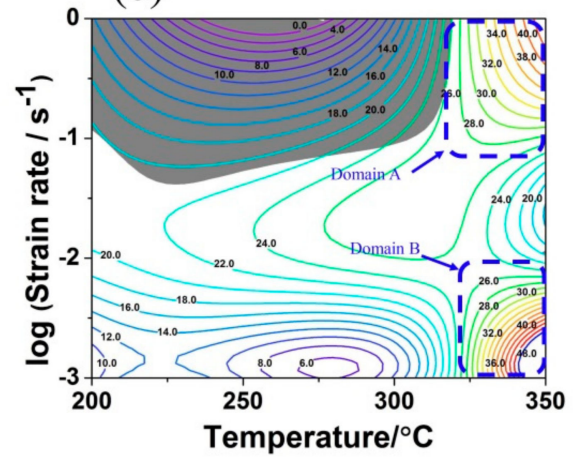

(d)

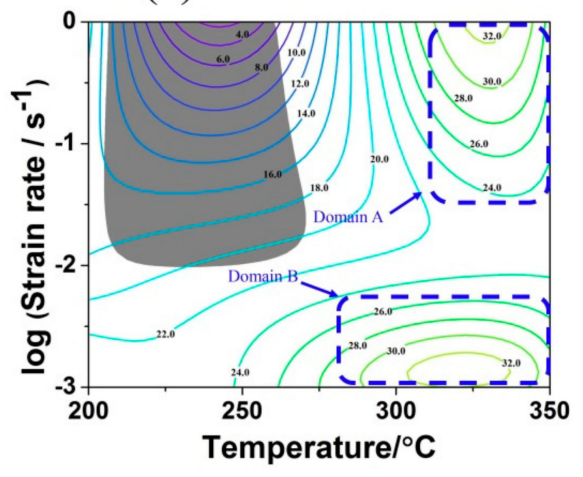

Figure 5. The hot processing maps of homogenized TAZ321 alloy at the true strain of (a) 0.2 , (b) 0.4 , (c) 0.6 , and (d) 0.8 . 
Figure $6 \mathrm{a}, \mathrm{c}$ shows the EBSD maps of the samples deformed at $350{ }^{\circ} \mathrm{C} / 10^{-3} \mathrm{~s}^{-1}$ and $350{ }^{\circ} \mathrm{C} / 1 \mathrm{~s}^{-1}$, corresponding to the domain B and A with the high $\eta$ values in the processing map, respectively. Compared to the as-homogenized alloy, the post-deformation samples at $350{ }^{\circ} \mathrm{C} / 10^{-3} \mathrm{~s}^{-1}$ exhibit a smaller grain size with an average grain size of $26.68 \mu \mathrm{m}$, which was attributed to the appearance of DRX. With the strain rate increased to $1 \mathrm{~s}^{-1}$, the DRX grains become more homogeneous and the average grain size decreased to $21.17 \mu \mathrm{m}$. This was due to DRX, which plays an important role in refining microstructure and improving mechanical properties [26]. Thus, based on the hot process map and microstructure, the domain A with homogeneous DRX grains can be determined as an optimum workability domain for the as-homogenized TAZ321 alloy.

(a)

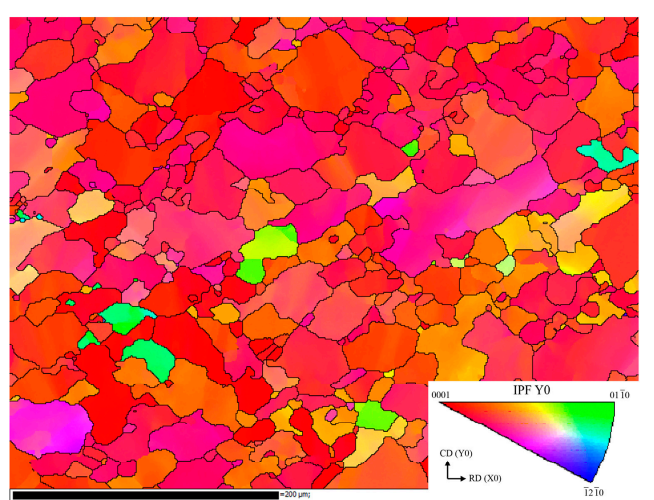

(c)

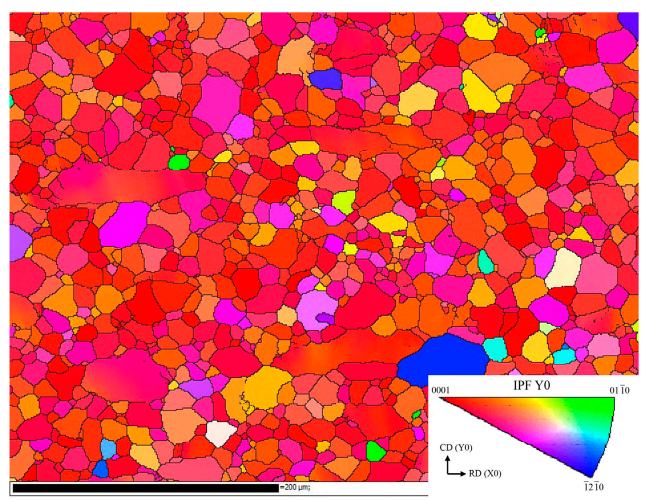

(b)

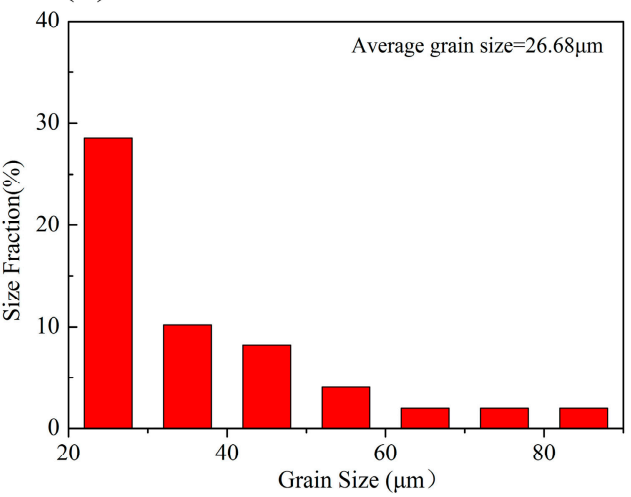

(d)

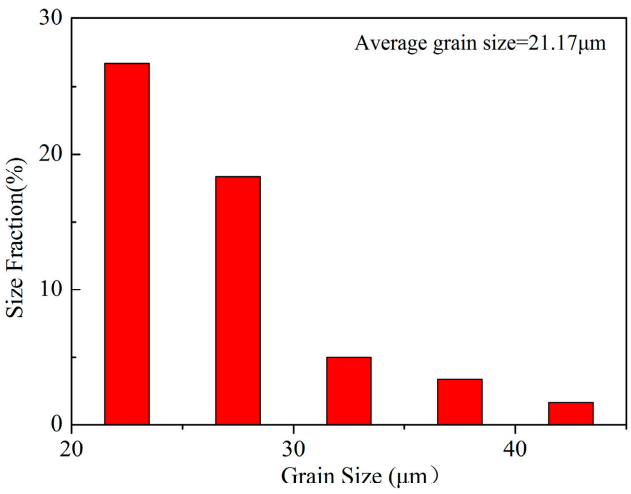

Figure 6. Inverse pole Figures (IPF) and grain distribution statistics of the samples deformation at (a,b) $350{ }^{\circ} \mathrm{C} / 10^{-3} \mathrm{~s}^{-1}$; (c,d) $350{ }^{\circ} \mathrm{C} / 1 \mathrm{~s}^{-1}$. (In the IPF, the CD and RD refer to the compressive direction and rolling direction, respectively.).

For the DRX, it is commonly believed that discontinuous DRX (DDRX) and continuous DRX (CDRX) are the main two mechanisms. Bulging original grain boundaries are the domain nucleation sites of DDRX. Meanwhile, the CDRX mechanism is characterized as the continuous absorption of dislocations in low-angle grain boundaries (subgrain boundaries) and followed by the progressive rotation of subgrains, which leads to the formation of high-angle grain boundaries (HAGBs) $[5,6]$. Figure $7 \mathrm{a}, \mathrm{b}$ shows the GB maps of the post samples deformed at $350{ }^{\circ} \mathrm{C} / 10^{-3} \mathrm{~s}^{-1}$ and $350{ }^{\circ} \mathrm{C} / 1 \mathrm{~s}^{-1}$, respectively. As indicated, no obvious grain boundaries bulging was observed and the formation of subgrains (grain boundaries from 2 to $10^{\circ}$ ) signifies the occurrence of continuous DRX (CDRX) in the alloy. Furthermore, the subgrain evolution can be evaluated by the changes of local misorientaion (point to point) and cumulative misorientaion (point to origin) [27]. Figure 8a-d indicate the location misorientation (black lines) and cumulative misorientation (red line) along the $\mathrm{AB}, \mathrm{CD}, \mathrm{EF}$, and $\mathrm{GH}$ lines, respectively. From Figure 8, it can be found that the values of local misorientation along the 
grain boundaries and in the grain interior did not extend beyond 5 degrees, while the cumulative misorientations are high, indicating a large increase in misorientation. Adequate misorientations can promote the subgrain rotation needed to form HAGBs.

(a)

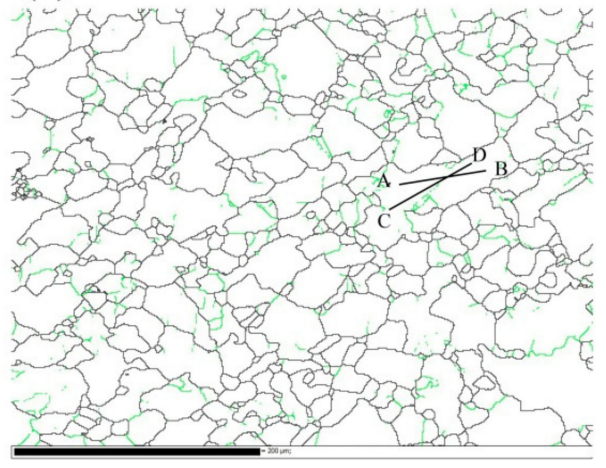

(b)

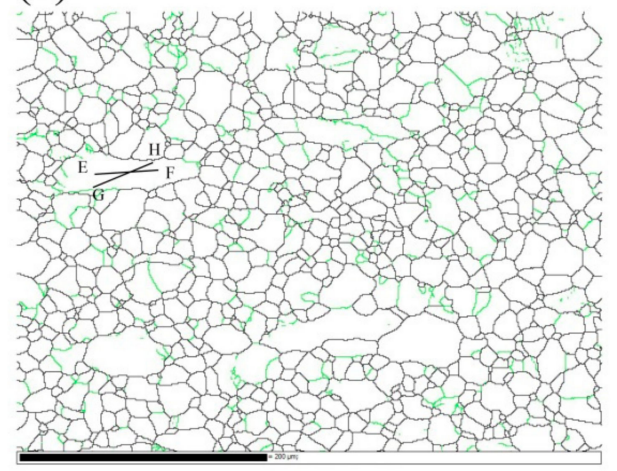

Figure 7. The grain boundary (GB) distribution maps of homogenized TAZ321 alloy at (a) $350{ }^{\circ} \mathrm{C} / 10^{-3} \mathrm{~s}^{-1}$; and (b) $350{ }^{\circ} \mathrm{C} / 1 \mathrm{~s} \mathrm{~s}^{-1}$ (grain boundaries from 2 to $15^{\circ}$ are in green and high angle boundaries that are $>15^{\circ}$ are in black).

(a)

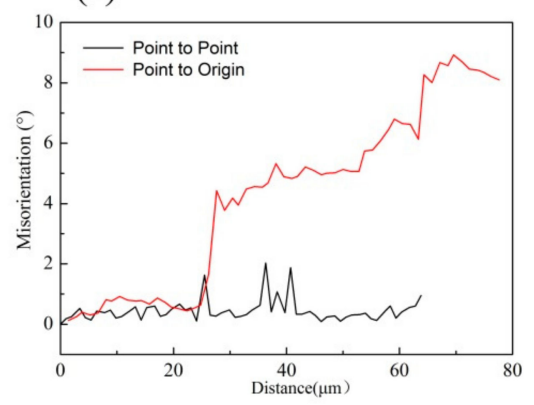

(c)

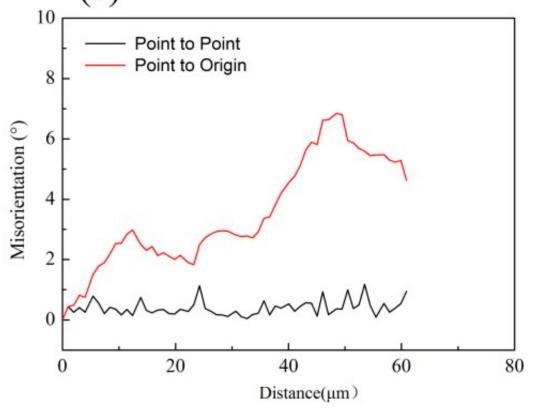

(b)

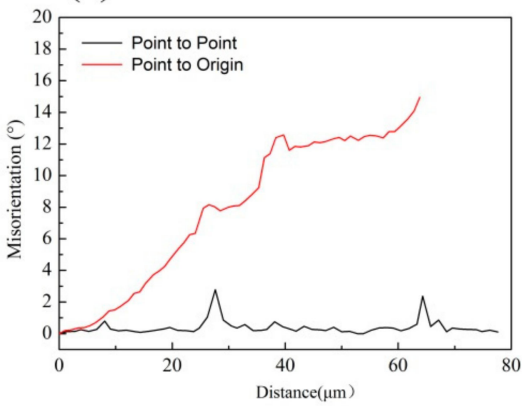

(d)

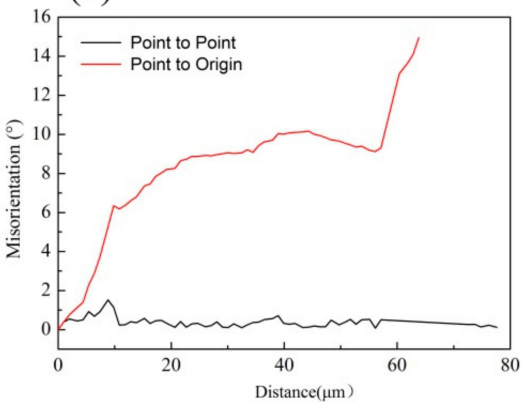

Figure 8. Misorientations measured along the lines of (a) AB, (b) CD, (c) EF, (d) GH.

The instability regions predicted by the processing map are mainly located at the median temperature regions, which were identified as $\mathrm{T}=200-300{ }^{\circ} \mathrm{C}, \dot{\varepsilon}=10^{-2}-1 \mathrm{~s}^{-1}$. Figure 9 a,b shows the $\mathrm{OM}$ images of the specimens compressed at $200^{\circ} \mathrm{C} / 10^{-2} \mathrm{~s}^{-1}$ and $250{ }^{\circ} \mathrm{C} / 10^{-1} \mathrm{~s}^{-1}$ at a true strain of 0.8 , respectively, corresponding to the microstructure of instability domains in the processing map. The microstructure of the samples deformed at the instability regions was characterized by deformation twining at the interior of grains and micro cracks along the intersection of grain boundaries, which were considered to be induced by flow localization. This was because deformation twining can induce local stress concentration and micro cracks can lead directly to fracture, which should be avoided during hot deformation [5]. 
(a)

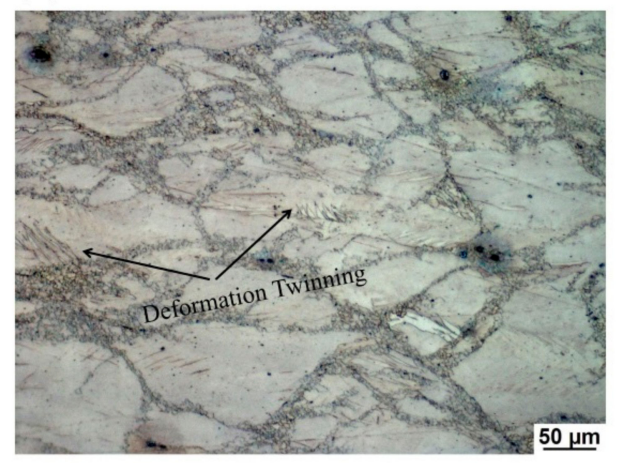

(b)

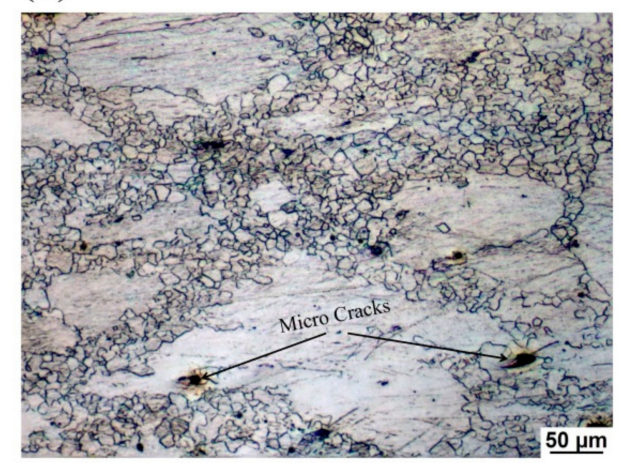

Figure 9. $\mathrm{OM}$ images of homogenized TAZ321 alloy deformed at the instability regions: (a) $200{ }^{\circ} \mathrm{C} / 10^{-2} \mathrm{~s}^{-1}$, (b) $250{ }^{\circ} \mathrm{C} / 10^{-1} \mathrm{~s}^{-1}$.

\section{Conclusions}

(1) The flow curves exhibited initially increase to a peak value and then decrease and finally reach a steady state. The serrations morphology of the flow curves is indicative for type B for the TAZ321 alloy, which was attributed to the interaction between the dislocations and the dynamic precipitation of $\mathrm{Mg}_{2} \mathrm{Sn}$ particles.

(2) The relationship between the flow stress, deformation temperature, and strain rate of homogenized TAZ321 alloy could be described by the constitutive equation as follows: $\dot{\varepsilon}=2.78 \times 10^{14} \cdot[\sinh (0.0012 \sigma)]^{6.14} \cdot \exp \left(-\frac{172110}{8.314 \mathrm{~T}}\right) \dot{\varepsilon}=4.75 \times 10^{11}[\sinh (0.004 \sigma)]^{4.11} \exp \left(-\frac{322300}{8.314 \mathrm{~T}}\right)$, the stress exponent $\mathrm{n}$ being 6.22 , suggesting that the dominant deformation mechanism was likely to be controlled by the cross-slipping of dislocation.

(3) According to the processing map, there were two stability domains with relatively high power dissipation efficiency: one was representing domain $\mathrm{A}\left(\mathrm{T}=310-350^{\circ} \mathrm{C}, \dot{\varepsilon}=10^{-1}-1 \mathrm{~s}^{-1}\right)$, and the other was denoted as domain $\mathrm{B}\left(\mathrm{T}=310-350{ }^{\circ} \mathrm{C}\right.$ and $\left.\dot{\varepsilon}=10^{-3}-10^{-2} \mathrm{~s}^{-1}\right)$. The optimum hot working domains were determined as being part of domain $\mathrm{A}\left(\mathrm{T}=310-350^{\circ} \mathrm{C}\right.$ and $\left.\dot{\varepsilon}=10^{-1}-1 \mathrm{~s}^{-1}\right)$ in combination with the hot processing map and microstructure observation, which corresponded to the microstructure of fine CDRX grains.

(4) The instability regions predicted by the processing map were identified as $\mathrm{T}=200-300{ }^{\circ} \mathrm{C}$, $\dot{\varepsilon}=10^{-2}-1 \mathrm{~s}^{-1}$. Deformation twinning or micro-cracks at the intersection of grain boundaries were observed in the instability domains.

(5) The TAZ321 alloy deformed at $350^{\circ} \mathrm{C} / 1 \mathrm{~s} \mathrm{~s}^{-1}$ exhibited more a homogeneous and finer grain size, and therefore were viewed strongly as a candidate for structural application.

Author Contributions: Conceptualization, Y.G. and S.Y.; methodology, Y.G.; software, Y.X.; validation, S.Y., Y.G. and X.L.; formal analysis, Y.X.; investigation, X.L.; resources, S.Y.; data curation, Y.G.; writing-original draft preparation, Y.G.; writing-review and editing, Y.G.; visualization, Y.X.; supervision, S.Y.; project administration, S.Y.; funding acquisition, S.Y. All authors have read and agreed to the published version of the manuscript.

Funding: This research received no external funding.

Conflicts of Interest: The authors declare no conflict of interest.

\section{References}

1. Nayyeri, G.; Mahmudi, R. Enhanced creep properties of a cast Mg-5Sn alloy subjected to aging-treatment. Mater. Sci. Eng. A 2010, 527, 4613-4618. [CrossRef]

2. Liu, C.; Liu, C.; Chen, H.; Nie, J.-F. Heat-treatable Mg-9Al-6Sn-3Zn extrusion alloy. J. Mater. Sci. Technol. 2018, 34, 284-290. [CrossRef] 
3. Prasad, Y.V.R.K.; Rao, K.P.; Hort, N.; Kainer, K.U. Hot working parameters and mechanisms in as-cast Mg-3Sn-1Ca alloy. Mater. Lett. 2008, 62, 4207-4209. [CrossRef]

4. Rao, K.P.; Prasad, Y.V.R.K.; Hort, N.; Kainer, K.U. Hot workability characteristics of cast and homogenized Mg-3Sn-1Ca alloy. J. Mater. Process. Technol. 2008, 201, 359-363. [CrossRef]

5. Cheng, W.; Bai, Y.; Ma, S.; Wang, L.; Wang, H.; Yu, H. Hot deformation behavior and workability characteristic of a fine-grained Mg-8Sn-2Zn-2Al alloy with processing map. J. Mater. Sci. Technol. 2019, 35, 1198-1209. [CrossRef]

6. Cheng, W.; Tian, Q.; Yu, H.; You, B.S.; Wang, H. Optimum parameters and kinetic analysis for hot working of a homogenized Mg-8Sn-1Al-1Zn alloy. Mater. Des. 2015, 85, 762-770. [CrossRef]

7. Koundinya, N.T.B.N.; Raman, L.; E, N.K.; Chawake, N.; Kottada, R.S. Hot deformation behaviour of Mg-3Al-3Sn and Mg-3Al-3Sn-1 Zn Alloys: Role of Zn. Materialia 2018, 3, 274-287. [CrossRef]

8. Liu, H.; Chen, Y.; Tang, Y.; Wei, S.; Niu, G. The microstructure, tensile properties, and creep behavior of as-cast Mg-(1-10)\%Sn alloys. J. Alloy. Compd. 2007, 440, 122-126. [CrossRef]

9. Huang, Z.H.; Zhou, N.; Xu, J.; Li, Y.D.; Li, W.R. Microstructure and Mechanical Property of Mg-Sn-Al Wrought Magnesium Alloys. Mater. Sci. Forum 2017, 898, 97-103. [CrossRef]

10. Sasaki, T.T.; Oh-ishi, K.; Ohkubo, T.; Hono, K. Enhanced age hardening response by the addition of Zn in Mg-Sn alloys. Scr. Mater. 2006, 55, 251-254. [CrossRef]

11. Luo, D.; Wang, H.-Y.; Chen, L.; Liu, G.-J.; Wang, J.-G.; Jiang, Q.-C. Strong strain hardening ability in an as-cast Mg-3Sn-1Zn alloy. Mater. Lett. 2013, 94, 51-54. [CrossRef]

12. Zhou, S.S.; Deng, K.K.; Li, J.C.; Nie, K.B.; Xu, F.J.; Zhou, H.F.; Fan, J.F. Hot deformation behavior and workability characteristics of bimodal size SiCp/AZ91 magnesium matrix composite with processing map. Mater. Des. 2014, 64, 177-184. [CrossRef]

13. Wu, S.K.; Chien, C.; Yang, C.S.; Bor, H.Y. The Portevin-Le Chatelier effect in $\beta$-phase Mg-14.3Li-0.8Zn alloy. Mater. Sci. Eng. A 2014, 605, 33-38. [CrossRef]

14. Shukla, A.K.; Narayana Murty, S.V.S.; Sharma, S.C.; Mondal, K. The serrated flow and recrystallization in dispersion hardened $\mathrm{Cu}-\mathrm{Cr}-\mathrm{Nb}$ alloy during hot deformation. Mater. Sci. Eng. A 2016, 673, 135-140. [CrossRef]

15. Sellars, C.M.; Tegart, W.J.M. Hot workability. Int. Metall. Rev. 1972, 17, 1-24. [CrossRef]

16. Sarebanzadeh, M.; Mahmudi, R.; Roumina, R. Constitutive analysis and processing map of an extruded Mg-3Gd-1Zn alloy under hot shear deformation. Mater. Sci. Eng. A 2015, 637, 155-161. [CrossRef]

17. Wu, H.-Y.; Wu, C.-T.; Yang, J.-C.; Lin, M.-J. Hot workability analysis of AZ61 Mg alloys with processing maps. Mater. Sci. Eng. A 2014, 607, 261-268. [CrossRef]

18. Spigarelli, S.; El Mehtedi, M. High-temperature deformation and creep in Mg wrought alloys. Scr. Mater. 2010, 63, 704-709. [CrossRef]

19. Prasad, Y.V.R.K.; Seshacharyulu, T. Modelling of hot deformation for microstructural control. Int. Mater. Rev. 1998, 43, 243-258. [CrossRef]

20. Fan, J.K.; Kou, H.C.; Lai, M.J.; Tang, B.; Chang, H.; Li, J.S. Characterization of hot deformation behavior of a new near beta titanium alloy: Ti-7333. Mater. Des. 2013, 49, 945-952. [CrossRef]

21. Sen, I.; Kottada, R.S.; Ramamurty, U. High temperature deformation processing maps for boron modified Ti-6Al-4V alloys. Mater. Sci. Eng. A 2010, 527, 6157-6165. [CrossRef]

22. Zhang, J.; Di, H.; Mao, K.; Wang, X.; Han, Z.; Ma, T. Processing maps for hot deformation of a high-Mn TWIP steel: A comparative study of various criteria based on dynamic materials model. Mater. Sci. Eng. A 2013, 587, 110-122. [CrossRef]

23. Wan, Z.; Hu, L.; Sun, Y.; Wang, T.; Li, Z. Hot deformation behavior and processing workability of a Ni-based alloy. J. Alloy. Compd. 2018, 769, 367-375. [CrossRef]

24. Prasad, Y.; Rao, K.; Sasidhar, S. Hot Working Guide: A Compendium of Processing Maps; ASM International: Cleveland, OH, USA, 2015.

25. Chen, Q.; Xia, X.; Yuan, B.; Shu, D.; Zhao, Z.; Han, J. Hot workfability behavior of as-cast Mg-Zn-Y-Zr alloy. Mater. Sci. Eng. A 2014, 593, 38-47. [CrossRef] 
26. Xu, T.C.; Peng, X.D.; Qin, J.; Chen, Y.F.; Yang, Y.; Wei, G.B. Dynamic recrystallization behavior of Mg-Li-Al-Nd duplex alloy during hot compression. J. Alloy. Compd. 2015, 639, 79-88. [CrossRef]

27. Guo, N.N.; Wang, L.; Luo, L.S.; Li, X.Z.; Chen, R.R.; Su, Y.Q.; Guo, J.J.; Fu, H.Z. Hot deformation characteristics and dynamic recrystallization of the MoNbHfZrTi refractory high-entropy alloy. Mater. Sci. Eng. A 2016, 651, 698-707. [CrossRef]

(C) 2020 by the authors. Licensee MDPI, Basel, Switzerland. This article is an open access article distributed under the terms and conditions of the Creative Commons Attribution (CC BY) license (http://creativecommons.org/licenses/by/4.0/). 